\title{
Effect of Acidosis on Chloride Transport in the Cortical Thick Ascending Limb of Henle Perfused In Vitro
}

\author{
Charles S. Wingo \\ Division of Nephrology and Hypertension, University of Florida, and the Medical Service, \\ Veterans Administration Medical Center, Gainesville, Florida 32602
}

\begin{abstract}
The present studies examined the effect of acute in vitro acidosis on chloride reabsorption in the rabbit cortical thick ascending limb of Henle (cTALH). Four protocols were used: $(a)$ hypercapnic acidosis; (b) "isocapnic" peritubular acidosis (bath bicarbonate reduction to $10 \mathrm{mM}$ ); (c) isocapnic luminal acidosis (luminal bicarbonate reduction to $10 \mathrm{mM}$ ); $(d)$ isocapnic peritubular acidosis in the absence of luminal potassium. Transepithelial voltage $\left(V_{\mathrm{T}}\right)$ decreased during hypercapnic acidosis and increased with recovery. Chloride reabsorption $\left(\mathrm{pmol} \cdot \mathrm{mm}^{-1}\right.$. $\mathrm{min}^{-1}$ ) decreased from $50.3 \pm 8.4$ to $15.7 \pm 5.6$, then increased to $45.6 \pm 11.1$ with recovery. Likewise, $V_{T}$ was decreased reversibly during isocapnic peritubular acidosis, and chloride reabsorption decreased by $60 \%$. Chloride reabsorption was greater (28.3 \pm 3.6$)$ when tubules were perfused at normal luminal $\mathrm{pH}$ than at an acidotic luminal pH (11.4 $\pm 4.5 ; P<0.05)$. Luminal potassium removal reduced chloride transport, and acidosis had no significant additional effect. Decreased chloride reabsorption in the cTALH during acidosis could contribute to the chloruresis associated with systemic acidosis. The symmetrical nature of this effect suggests that acidosis inhibits chloride reabsorption through an effect on cytosolic pH.
\end{abstract}

\section{Introduction}

Acidosis of either respiratory or metabolic origin is associated with chloruresis and natriuresis $(1,2)$. Recent evidence suggests that acidosis decreases chloride transport in the proximal tubule (3) and sodium transport in post-proximal segments (4), including the cortical collecting tubule (5). However, it has not been determined whether acid-base changes affect sodium chloride transport in the thick ascending limb of Henle. Therefore, the present studies examined this issue using in vitro microperfusion. Separate protocols were designed to examine the effect of hypercapnic acidosis and "isocapnic" acidosis due to reduction in bicarbonate concentration in either the luminal or peritubular fluid. The changes in pH produced were similar to those encountered in clinical medicine.

\section{Methods}

Female New Zealand White rabbits (1-2 kg) were maintained on standard rabbit ration (Ralston Purina Co., St. Louis, MO) and allowed free access to water until they were killed.

Address all correspondence to Charles S. Wingo, 111G, Veterans Administration Medical Center, Gainesville, FL 32602.

Received for publication 4 December 1984 and in revised form 24 June 1986.

The Journal of Clinical Investigation, Inc.

Volume 78, November 1986, 1324-1330
Segments of cortical thick ascending limbs of Henle (cTALH) ${ }^{1}$ were perfused in vitro as originally described by Burg et al. (6). Rabbits were decapitated, one kidney was quickly removed, and 1-2-mm-thick slices were placed in a chilled petri dish containing an artificial filtrate of plasma. The solution contained the following concentrations (in millimoles per liter): sodium, 145; potassium, 5; chloride, 112; bicarbonate, 24; calcium, 2.0; phosphorus, 1.5; magnesium, 1; sulfate, 1; acetate, 10; glucose, 8; alanine, 5 . This solution was designated solution A. Unless otherwise specified, the dissection, bath, and perfusion solutions were identical with the exception that $5 \% \mathrm{vol} / \mathrm{vol}$ fetal calf serum was added to the dissection and bath solutions. The perfusate contained $50 \mu \mathrm{Ci} \cdot \mathrm{ml}^{-1}$ of methoxy-tritiated inulin exhaustively dialyzed according to the method of Schafer et al. (7). Unless otherwise specified, all solutions were gassed to $\mathrm{pH} 7.4$ with a $95 \% \mathrm{O}_{2}$ and $5 \% \mathrm{CO}_{2}$ mixture. Three other solutions were used in these experiments. Solution B was identical to solution A except that $14 \mathrm{mM} \mathrm{Na}$ benzenesulfonate replaced $14 \mathrm{mM} \mathrm{NaHCO}_{3}$ for a final $\left[\mathrm{HCO}_{3}\right]$ of $10 \mathrm{mM}$. Solution $\mathrm{C}$ was identical to solution $\mathrm{A}$ except that $14 \mathrm{mM} \mathrm{NaCl}$ replaced $14 \mathrm{mM} \mathrm{NaHCO}$ for a final $\left[\mathrm{HCO}_{3}\right]$ of 10 $\mathrm{mM}$. Solution D was identical to solution A except that $19 \mathrm{mM} \mathrm{Na}$ benzenesulfonate replaced $19 \mathrm{mM} \mathrm{NaHCO}_{3}$ for a final $\left[\mathrm{HCO}_{3}\right]$ of $5 \mathrm{mM}$.

Dissection proceeded superficially from the cortical-medullary junction. Tubules were transferred to a thermostat-controlled chamber, and the two ends of the tubule were aspirated into holding pipettes. The perfusing pipette was advanced $\sim 100 \mu \mathrm{m}$ beyond the holding pipette. Transepithelial voltage $\left(V_{\mathrm{T}}\right)$ was monitored as described by Jacobson and Kokko (8). Perfusate traversed the tubule and was collected under water-equilibrated mineral oil in a constant volume pipette. The bath fluid was continuously exchanged by means of a constant infusion pump at a rate of $0.64 \mathrm{ml} \cdot \mathrm{min}^{-1}$. Volume reabsorption was determined from timed measurements of the collected fluid using the equation $J_{\mathrm{v}}=(\mathrm{cpm} /$ $\left.c p m_{\mathrm{i}}-1\right) \cdot V_{\mathrm{o}} / L$, where $J_{\mathrm{v}}$ is net volume of reabsorption in $\mathrm{nl} \cdot \mathrm{mm}^{-1} \cdot \mathrm{min}^{-1}$, and $c p m_{\mathrm{o}}$ and $c p m_{\mathrm{i}}$ are the respective tritiated inulin counts per minute per nanoliter in the collected and perfused fluid. $V_{0}$ is the collected fluid rate (in nanoliters per minute), and $L$ is the tubular length (in millimeters). In all experiments the absolute magnitude of volume reabsorption was $<0.1 \mathrm{nl} \cdot \mathrm{mm}^{-1} \cdot \mathrm{min}^{-1}$. Chloride concentration of the perfused and collected fluid was measured by electrotitration (9) (model ET1 electrotitrator; World Precision Instruments, Inc., New Haven, CT). This instrument displayed a linear response over the entire sample range, employing three $\mathrm{NaCl}$ standards $(50,100,150 \mathrm{meq} / \mathrm{liter})$. Since volume reabsorption was negligible under the conditions of these experiments, net chloride reabsorption ( $J_{\mathrm{C}}^{\text {pet }}$ ) was calculated as follows: $J_{\mathrm{Cl}}^{\text {net }}=\left([\mathrm{Cl}]_{\mathrm{i}}-[\mathrm{Cl}]_{\mathrm{o}}\right) \cdot V_{\mathrm{o}} / L$, where $[\mathrm{Cl}]_{\mathrm{i}}$ and $[\mathrm{Cl}]_{\mathrm{o}}$ are the chloride concentrations in milliequivalents per liter of the perfused and collected fluid, respectively. Chloride analysis was performed in triplicate.

$V_{\mathrm{T}}$ was adjusted to zero at the beginning of the experiment, before tubule cannulation in symmetrical solutions (with $5 \%$ fetal calf serum in the bath), and was rechecked upon the completion of the experiment under asymmetrical conditions. The latter value was within $1.5 \mathrm{mV}$, and usually within $1 \mathrm{mV}$, of zero. Under asymmetrical conditions the recorded $V_{\mathrm{T}}$ represents the sum of the transepithelial voltage and a liquid junction potential, $E_{\mathrm{L}}$. All voltage measurements are reported without correction for $E_{\mathrm{L}}$. The bi-ionic liquid junction potential for both chloride

1. Abbreviations used in this paper: cTALH, cortical thick ascending limb of Henle; mTALH, medullary thick ascending limb of Henle; $V_{\mathrm{T}}$, transepithelial voltage. 
and benzenesulfonate substitution for bicarbonate can be estimated from the Henderson equation $(10,11)$ :

$E_{\mathrm{L}}=\frac{R T}{F} \cdot \frac{\Sigma\left(u_{\mathrm{i}} / z_{\mathrm{i}}\right)\left(a_{\mathrm{i}}^{\prime \prime}-a_{\mathrm{i}}^{\prime}\right)}{\Sigma u_{\mathrm{i}}\left(a_{\mathrm{i}}^{\prime \prime}-a_{\mathrm{i}}^{\prime}\right)} \cdot \ln \frac{\Sigma a_{\mathrm{i}}^{\prime} u_{\mathrm{i}}}{\Sigma a_{\mathrm{i}}^{\prime \prime} u_{\mathrm{i}}}$

using activities rather than concentrations. Activities coefficients can be estimated from the Debye-Hückel equation:

$\log f_{\mathrm{i}}=\frac{-A \cdot z_{\mathrm{i}}^{2} \cdot I^{1 / 2}}{1+\beta \cdot a_{\mathrm{i}} \cdot I^{1 / 2}}$

where $A=0.5056, \beta=0.3286 \times 10^{8}$ at $25^{\circ} \mathrm{C}(11) . a_{\mathrm{i}}$ may be considered the effective diameter of the hydrated ion $\mathrm{i}(12)$. The values from this formula are similar to measured activities for chloride and bicarbonate (13). In the case of benzenesulfonate, the activity coefficient was estimated from the extension of the Debye-Hückel equation proposed by Kielland (12). Limiting mobilities of chloride and bicarbonate at $25^{\circ} \mathrm{C}$ were obtained from tables (13), and the limiting mobility of benzenesulfonate at $25^{\circ} \mathrm{C}$ was approximated from molecules of similar structure, size, and charge. Sensitivity analysis disclosed that $E_{\mathrm{L}}$ exhibited little change over a reasonable range of estimated values for the limiting mobility of benzenesulfonate. In addition, this $E_{\mathrm{L}}$ was measured directly, using a silver/ silver-chloride-saturated potassium chloride electrode system. This measured value, $0.2 \mathrm{mV}$, compares favorably with the value derived from the Henderson equation. The calculated liquid junction potential for the bicarbonate substitution experiments with chloride was $-0.7 \mathrm{mV}$. In the case of bicarbonate substitution with benzenesulfonate, the $V_{\mathrm{T}}$ should be corrected by $+0.3 \mathrm{mV}$ for the bath substitution experiments and by $-0.3 \mathrm{mV}$ for the luminal substitution experiments. Since these corrections are small, and since numerous assumptions are necessary for the calculation of the liquid junction potential, the reported $V_{\mathrm{T}}$ represents that which was directly observed.

In the four protocols used in this study, tubules were perfused at $37 \pm 0.5^{\circ} \mathrm{C}$ for $30 \mathrm{~min}$ before obtaining control collections for volume reabsorption and chloride analysis. In the first protocol (hypercapnic acidosis), the bath was exchanged for one identical in composition but gassed with $10 \% \mathrm{CO}_{2}, 90 \% \mathrm{O}_{2}$. After a 15 -min equilibration period, three or more collections were obtained for volume reabsorption and chloride analysis. The bath was then exchanged for the original solution, and after another 15-min equilibration period, recovery collections were obtained. In the second protocol (isocapnic peritubular acidosis) the bath bicarbonate concentration was decreased to $10 \mathrm{mM}$ during the experimental period by exchanging solution A for either solution $B$ or solution C. The protocol was otherwise similar to the preceding one. In the third protocol (isocapnic luminal acidosis) the luminal bicarbonate concentration was reduced to $10 \mathrm{mM}$ by substitution with benzenesulfonate (solution B). After a 15-min equilibration, collections were obtained for volume reabsorption and chloride analysis. The order of the acidotic and the normal $\mathrm{pH}$ periods was randomized. In the fourth protocol (isocapnic peritubular acidosis without luminal $\mathrm{K}$ ) tubules were perfused with the normal pH perfusate (solution $\mathrm{A}$ ) except that $5 \mathrm{mM} \mathrm{KCl}$ was omitted from the perfusate (solution $\mathrm{A}^{\prime}$ ). The tubules were bathed in random order with either solution $A$ (including potassium chloride) or solution $\mathrm{D}$ (including potassium chloride). At least three collections were made for volume reabsorption and chloride analysis, and the bath solution was exchanged for the other solution. After a 15-min equilibration, collections were obtained for volume reabsorption and chloride analysis.

Perfusate and bath solutions were placed in syringes immediately after gassing and were analyzed for $\mathrm{pH}, \mathrm{PCO}_{2}$, and bicarbonate concentration within 15 min on an IL blood gas analyzer, model 713 (Allied Chemical Corp., Analytical Systems Div., Waltham, MA). Paired samples were analyzed again upon completion of the experiment and showed no significant alteration in acid-base composition.

The $\mathrm{pH}$ means for each experimental protocol are given as follows. For hypercapnic acidosis, $\mathrm{pH}=7.46 \pm 0.02$, control, and $\mathrm{pH}=7.16 \pm 0.01$, acidosis; for isocapnic peritubular acidosis, $\mathrm{pH}=7.47 \pm 0.009$, control, and $\mathrm{pH}=7.12 \pm 0.007$, acidosis; for isocapnic luminal acidosis, $\mathrm{pH}$ $=7.43 \pm 0.02$, control, and $\mathrm{pH}=7.12 \pm 0.005$, acidosis; for isocapnic peritubular acidosis in the absence of luminal potassium, $\mathrm{pH}$ $=7.45 \pm 0.005$, control, and $\mathrm{pH}=6.88 \pm 0.01$, acidosis. The values were obtained directly from the blood gas analyzer. To be certain that the reported $\mathrm{pH}$ values accurately reflected the $\mathrm{pH}$ in the bath during these experiments, the experimental protocol was repeated exactly and the $\mathrm{pH}$ of the bath was monitored using a miniature $\mathrm{pH}$ electrode (Microelectrodes Inc., Londonderry, $\mathrm{NH}$ ). The $\mathrm{pH}$ electrode was positioned at the location of the collecting pipette in the bath. It was calibrated at $37^{\circ} \mathrm{C}$ using three reference standards $(\mathrm{pH}=4.0,7.4,10.0)$ and was linear over this entire $\mathrm{pH}$ range (coefficient of determination $=0.9993$ ). The solutions and $\mathrm{pH}$ measured by this $\mathrm{pH}$ electrode placed directly in the perfusion bath are listed in Table $\mathrm{I}$. In separate experiments, the $\mathrm{pH}$ of the bath was monitored as a function of time. The $\mathrm{pH}$ of the bath was very stable with time. The maximum $\mathrm{pH}$ increase registered as $0.04 \mathrm{pH}$ units after 60 min of perfusion (solution A: time $0, \mathrm{pH}=7.43 \pm 0.01$, time $60, \mathrm{pH}$ $=7.47 \pm 0.01$; solution $\mathrm{B}$ : time $0, \mathrm{pH}=7.08 \pm 0.01$, time $60, \mathrm{pH}$ $=7.12 \pm 0.01$ ).

Statistical analyses were performed using analysis of variance, multiple regression analysis, or $t$ test for paired or unpaired data as appropriate. The null hypothesis was rejected at the 0.05 level of significance.

\section{Results}

There was no significant change in $J_{\mathrm{v}}$ for any of the control, experimental, and recovery periods. The mean $J_{\mathrm{v}}$ in $\mathrm{nl} \cdot \mathrm{mm}^{-1} \cdot \mathrm{min}^{-1}$ was $-0.04 \pm 0.01$ for the hypercapnic acidosis protocol (solution $\mathrm{A}$ ), $-0.01 \pm 0.01$ for the isocapnic peritubular acidosis protocol $(-0.03 \pm 0.01$ for the benzenesulfonate substitution subgroup [solution $B$ ] and $0.03 \pm 0.04$ for the chloride substitution subgroup [solution $C$ ]), $0.002 \pm 0.02$ for the isocapnic luminal acidosis protocol (solution B), and $-0.05 \pm 0.02$ for the final protocol (solution D). Thus, changes in volume reabsorption could account for no more than $13 \%$ of the observed changes in chloride transport due to acidosis.

The effect of hypercapnic acidosis (solution $\mathrm{A}$ ) on $V_{\mathrm{T}}$ is illustrated in Fig. 1. $V_{\mathrm{T}}$ decreased from a mean value of $4.6 \pm 1.1$ $\mathrm{mV}$ during the control period to $0.9 \pm 0.5 \mathrm{mV}(P<0.05)$ with acidosis and increased to $2.1 \pm 0.7 \mathrm{mV}(P<0.05)$ with recovery. Fig. 2 illustrates the effect of hypercapnic acidosis on net chloride reabsorption. Chloride reabsorption during the control period averaged $50.3 \pm 8.4 \mathrm{pmol} \cdot \mathrm{mm}^{-1} \cdot \mathrm{min}^{-1}$ and decreased to $15.7 \pm 5.6 \mathrm{pmol} \cdot \mathrm{mm}^{-1} \cdot \mathrm{min}^{-1}(P<0.05)$ with exposure to $10 \%$ $\mathrm{CO}_{2}, 90 \% \mathrm{O}_{2}$. With recovery, there was a substantial increase in net chloride reabsorption to $45.6 \pm 11.1 \mathrm{pmol} \cdot \mathrm{mm}^{-1} \cdot \mathrm{min}^{-1}$ $(P<0.05)$. The relation between chloride reabsorption and luminal flow rate is illustrated in Fig. 3. There was a significant correlation between chloride reabsorption and axial flow rate in seven tubules for both control periods and acidotic periods. One

Table I. Direct Measurement of Bath pH as Monitored by Glass-Membrane pH Electrode

\begin{tabular}{llllll}
\hline Solution & {$[\mathrm{Cl}]$} & {$\left[\mathrm{HCO}_{3}\right]$} & {$[\mathrm{BS}]^{*}$} & Gassing mixture & $\begin{array}{l}\text { pH of solution } \\
\text { in bath }\end{array}$ \\
\hline & $m M$ & $m M$ & $m M$ & & \\
A & 112 & 24 & 0 & $95 \% \mathrm{O}_{2} / 5 \% \mathrm{CO}_{2}$ & $7.46 \pm 0.02$ \\
A & 112 & 24 & 0 & $90 \% \mathrm{O}_{2} / 10 \% \mathrm{CO}_{2}$ & $7.08 \pm 0.02$ \\
B & 112 & 10 & 14 & $95 \% \mathrm{O}_{2} / 5 \% \mathrm{CO}_{2}$ & $7.10 \pm 0.01$ \\
C & 126 & 10 & 0 & $95 \% \mathrm{O}_{2} / 5 \% \mathrm{CO}_{2}$ & $7.04 \pm 0.01$ \\
D & 112 & 5 & 19 & $95 \% \mathrm{O}_{2} / 5 \% \mathrm{CO}_{2}$ & $6.87 \pm 0.008$
\end{tabular}

* BS, benzenesulfonate. 


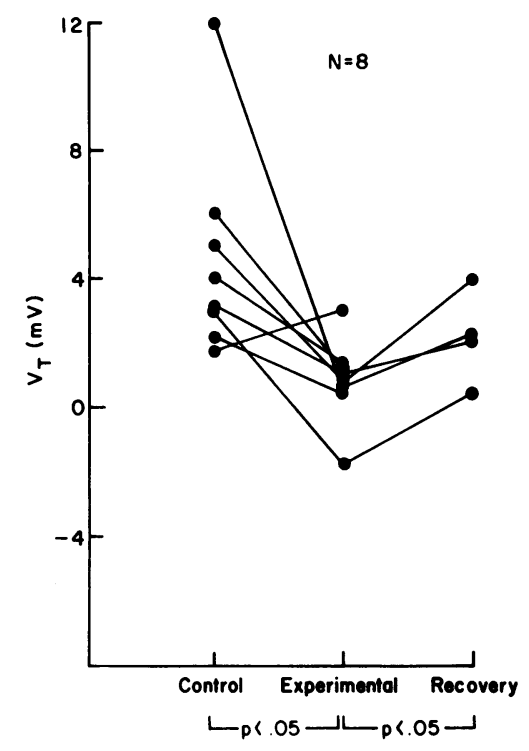

Figure 1. Effect of acidosis (increased $\mathrm{PCO}_{2}$ ) on $V_{\mathrm{T}}$ in cTALH. During the control and recovery periods, the bath $\mathrm{pH}$ was $7.46 \pm 0.02$ and the $\mathrm{PCO}_{2}$ was $37 \pm 1.5$ mmHg. During the experimental period the bath $\mathrm{pH}$ was $7.16 \pm 0.01$ and the $\mathrm{PCO}_{2}$ was $75 \pm 3.2 \mathrm{mmHg}$.

tubule was excluded from the analysis for both the control and acidotic periods. The two lines (Fig. 3) represent linear regression equations for the control and acidotic periods. Multiple regression analysis demonstrated that there were statistically significant separate effects of acidosis and luminal flow rate on chloride transport. Thus, at any given luminal flow rate, there was a significant reduction in chloride reabsorption in the acidotic group. Therefore, alteration in chloride reabsorption could not be ascribed simply to variation in tubular fluid flow rate. Furthermore, analysis of the luminal flow rates by paired $t$ test showed no significant difference in flow rates for the control versus acidosis or acidosis versus recovery period for any of the four protocols. The mean \pm SEM perfusion rate in nanoliters per minute in the hypercapnic acidosis protocol was $5.19 \pm 0.70,4.64 \pm 0.66$, and $6.57 \pm 0.97$ for the control, experimental, and recovery periods, respectively. For the isocapnic peritubular acidosis protocol, the respective perfusion rates were $3.48 \pm 0.38,3.53 \pm 0.38$, and $3.41 \pm 0.38$. (The values for the subgroup with chloride substitution [solution $C$ ] were $3.00 \pm 0.16,3.15 \pm 0.49$, and $3.40 \pm 0.84$. The values for the subgroup with benzenesulfonate substitution

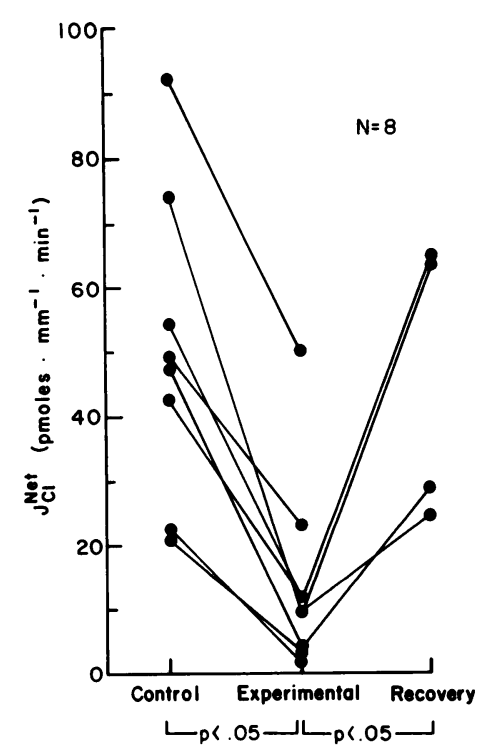

Figure 2. Effect of acidosis (increased $\mathrm{PCO}_{2}$ ) on chloride reabsorption $\left(J_{\mathrm{C}}^{\text {set }}\right)$ in cTALH. During the control and recovery periods, the bath $\mathrm{pH}$ was $7.46 \pm 0.02$ and the $\mathrm{PCO}_{2}$ was $37 \pm 1.5$ mmHg. During the experimental period the bath $\mathrm{pH}$ was $7.16 \pm 0.01$ and the $\mathrm{PCO}_{2}$ was $75 \pm 3.2 \mathrm{mmHg}$.

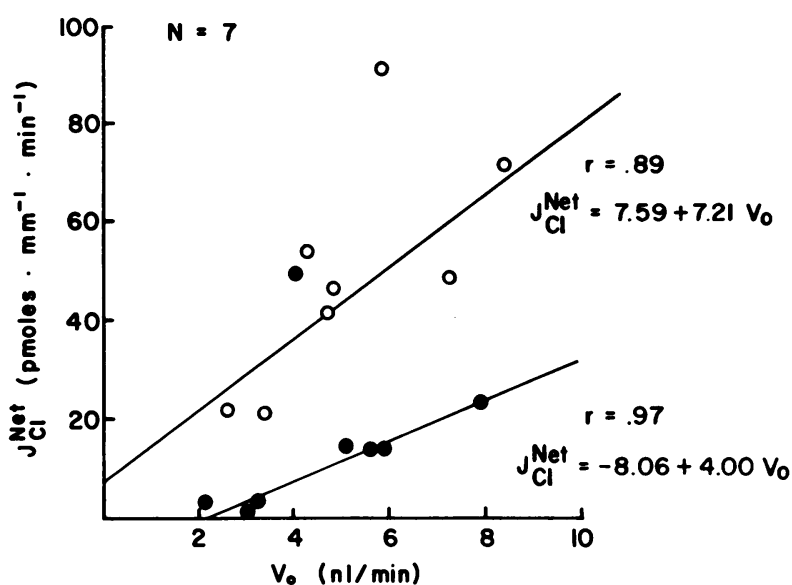

Figure 3. Relation between flow rate $\left(V_{0}\right)$ and chloride reabsorption $\left(J_{\mathrm{CI}}^{\text {net }}\right)$ in cTALH. One tubule exhibiting substantially greater transport for both the control and acidosis periods was excluded from the regression analysis.

[solution B] were $3.76 \pm 0.58,3.74 \pm 0.55$, and $3.42 \pm 0.43)$. In the isocapnic luminal acidosis protocol, the mean perfusion rate was $4.84 \pm 0.68$ during the control period (solution A) and $4.55 \pm 0.61$ during acidosis (solution $B$ ). The mean perfusion rate in the final protocol during the control period (solution $A$ ) was $4.52 \pm 0.71$, and during peritubular acidosis (solution $D$ ) it was $4.51 \pm 0.72$.

The next two sets of protocols were performed to examine the effects of selective luminal and peritubular acidosis due to a reduction in bicarbonate concentration. Fig. 4 illustrates the effect of isocapnic reduction in bath bicarbonate concentration on $V_{\mathrm{T}}$ (solutions B or $\mathrm{C}$ ). In these tubules, $V_{\mathrm{T}}$ declined slowly but consistently over the period of the experiment. The reason for this decline was not entirely obvious, but the tubules appeared to be morphologically normal. Peritubular acidosis, however, produced a clear decrease in $V_{\mathrm{T}}$, which was $3.5 \pm 0.4 \mathrm{mV}$ during the control period and averaged $0.37 \pm 0.38 \mathrm{mV}(P<0.05)$ during the period of peritubular acidosis. Moreover, there was a significant increase in $V_{\mathrm{T}}$ after reexposure to a normal $\mathrm{pH}$ bath $(1.6 \pm 0.7 \mathrm{mV})$. When the tubules in which benzenesulfonate replaced bicarbonate (solution B) were analyzed separately, $V_{\mathrm{T}}$ significantly decreased (from $3.1 \pm 0.3$ to $-0.1 \pm 0.5 \mathrm{mV} ; P<0.05$ ) and then significantly increased $(1.1 \pm 0.8 \mathrm{mV} ; P<0.05)$ with

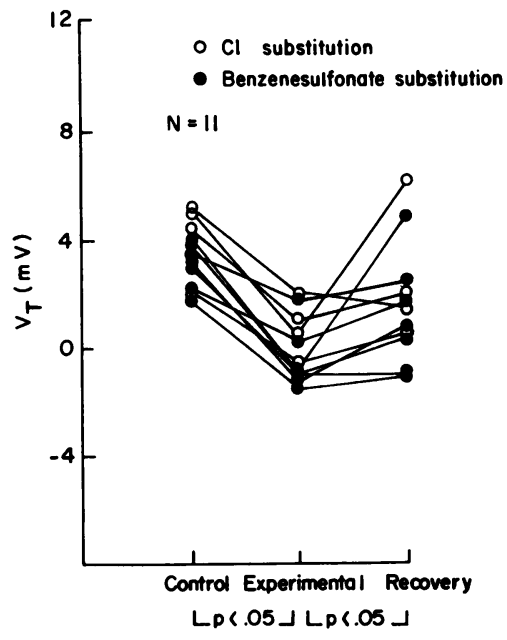

Figure 4. Effect of acidosis (decreased bath $\mathrm{HCO}_{3}$ ) on $V_{\mathrm{T}}$ in cTALH. During the control and recovery periods, the bath $\mathrm{pH}$ was $7.47 \pm 0.009$ and the $\left[\mathrm{HCO}_{3}\right]$ was $22.1 \pm 0.3$ mM. During the experimental period the bath $\mathrm{pH}$ was $7.12 \pm 0.007$ and the $\left[\mathrm{HCO}_{3}\right]$ was $10.3 \pm 0.3 \mathrm{mM}$. 
recovery. Fig. 5 illustrates the effect of isocapnic peritubular acidosis on chloride reabsorption. Chloride reabsorption decreased from $38.6 \pm 4.4 \mathrm{pmol} \cdot \mathrm{mm}^{-1} \cdot \mathrm{min}^{-1}$ during the control period to $12.6 \pm 2.9 \mathrm{pmol} \cdot \mathrm{mm}^{-1} \cdot \mathrm{min}^{-1}(P<0.05)$ after reducing the bath bicarbonate concentration to $10 \mathrm{mM}$. On reexposure to a normal bath $\mathrm{pH}$, chloride reabsorption increased to $26.2 \pm 5.6$ $\mathrm{pmol} \cdot \mathrm{mm}^{-1} \cdot \mathrm{min}^{-1}(P<0.05)$. The effect did not appear to be different whether chloride (solution $\mathrm{C}$ ) or benzenesulfonate (solution B) was substituted for bicarbonate. There was also a significant and reversible effect of acidosis on chloride transport for the tubules that were subjected to peritubular acidosis under symmetrical luminal and peritubular chloride concentrations (benzenesulfonate substitution, solution B). These tubules exhibited a significant decrease in chloride transport, from $37.6 \pm 7.0$ $\mathrm{pmol} \cdot \mathrm{mm}^{-1} \cdot \mathrm{min}^{-1}$ to $13.1 \pm 2.4 \mathrm{pmol} \cdot \mathrm{mm}^{-1} \cdot \min ^{-1}(P<0.05)$ during peritubular acidosis, which increased significantly on recovery, to $25.1 \pm 4.2 \mathrm{pmol} \cdot \mathrm{mm}^{-1} \cdot \mathrm{min}^{-1}(P<0.05)$.

The third protocol was designed to examine whether the effect of isocapnic (metabolic) acidosis was symmetrical or limited to the basolateral membrane. Luminal bicarbonate was replaced by benzenesulfonate in all these experiments (solution B). Fig. 6 illustrates the effect of isocapnic luminal bicarbonate reduction on $V_{\mathrm{T}}$. The mean $V_{\mathrm{T}}$ was $5.0 \pm 0.9 \mathrm{mV}$ during those periods when the $\mathrm{pH}$ of the perfusate was normal, and was significantly less, $2.5 \pm 1.0 \mathrm{mV}(P<0.05)$, during the acidotic period. Chloride reabsorption with both the normal and acidotic luminal $\mathrm{pH}$ is illustrated in Fig. 7. Chloride reabsorption was $28.3 \pm 3.6$ $\mathrm{pmol} \cdot \mathrm{mm}^{-1} \cdot \mathrm{min}^{-1}$ at a normal luminal $\mathrm{pH}$ compared with $11.4 \pm 4.5 \mathrm{pmol} \cdot \mathrm{mm}^{-1} \cdot \mathrm{min}^{-1}(P<0.05)$ during an acidotic $\mathrm{pH}$. The degree of inhibition of chloride transport was similar to the previous observations. Therefore, a selective effect of peritubular versus luminal acidosis could not be established.

The fourth protocol was designed to examine whether or not the inhibitory effect of acidosis required the presence of luminal potassium. Six tubules were perfused in the absence of luminal potassium (solution $\mathrm{A}^{\prime}$ ) and bathed in random order with either normal bicarbonate (solution $\mathrm{A}$ ) or a solution in which $19 \mathrm{meq} /$ liter of bicarbonate was replaced with benzene-

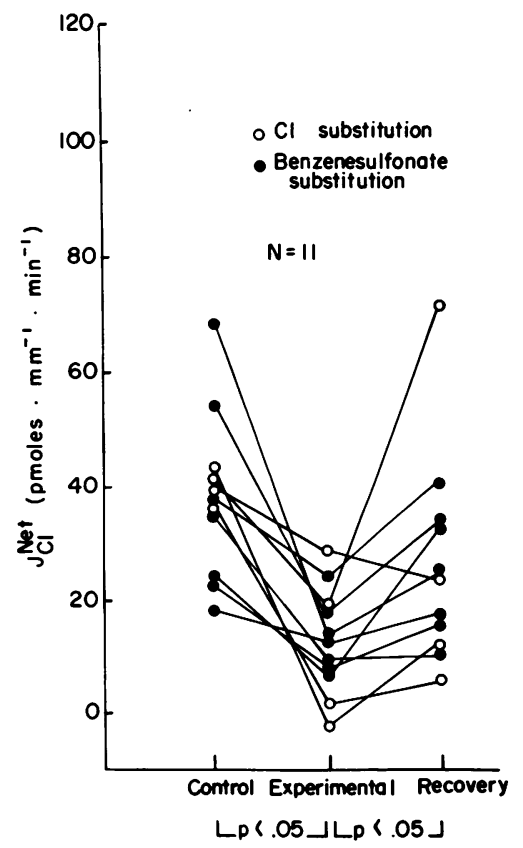

Figure 5. Effect of acidosis (decreased bath $\mathrm{HCO}_{3}$ ) on chloride reabsorption in CTALH. During the control and recovery periods, the bath $\mathrm{pH}$ was $7.47 \pm 0.009$ and the $\left[\mathrm{HCO}_{3}\right]$ was $22.1 \pm 0.3$ mM. During the experimental period the bath $\mathrm{pH}$ was $7.12 \pm 0.007$ and the $\left[\mathrm{HCO}_{3}\right]$ was $10.3 \pm 0.3 \mathrm{mM}$.

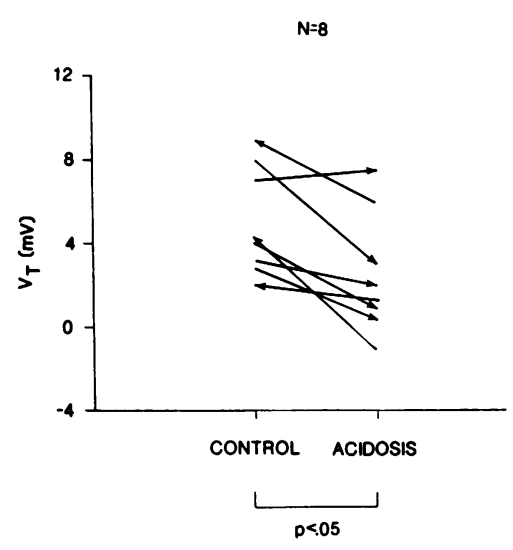

Figure 6. Effect of acidosis (decreased luminal $\mathrm{HCO}_{3}$ ) on $V_{\mathrm{T}}$ in cTALH. During the control and recovery periods, the luminal $\mathrm{pH}$ was $7.43 \pm 0.02$ and the $\left[\mathrm{HCO}_{3}\right]$ was $22.1 \pm 0.6$ mM. During the experimental period the luminal $\mathrm{pH}$ was $7.12 \pm 0.005$ and the $\left[\mathrm{HCO}_{3}\right]$ was $9.83 \pm 0.35$ $\mathrm{mM}$. The arrows denote the order in which the tubule was exposed to acidosis (arrowhead for second period).

sulfonate (solution D). Because previous reports suggested that chloride transport would be diminished under these circumstances, a greater degree of acidosis was chosen to enhance the possibility of observing a detectable change in effluent chloride concentration. The results of this protocol are given in Table II. Indeed, chloride transport was significantly less in the absence of luminal potassium $\left(8.68 \pm 4.06 \mathrm{pmol} \cdot \mathrm{mm}^{-1} \cdot \mathrm{min}^{-1}, P<0.05\right)$ during the normal $\mathrm{pH}$ period, and $V_{\mathrm{T}}$ was significantly less $(0.3 \pm 0.5 \mathrm{mV}, P<0.05)$ in these tubules than in tubules perfused with $5 \mathrm{mM}$ potassium. Despite a greater degree of acidosis during the experimental period, the decrease in chloride transport to $-19.5 \pm 12.0 \mathrm{pmol} \cdot \mathrm{mm}^{-1} \cdot \mathrm{min}^{-1}$ was not statistically significant. Further evaluation of these data by two-way analysis of variance for replicate samples, either with or without an interaction term, disclosed no significant effect on chloride transport of either the order in which the experiments were performed (acidosis first period vs. acidosis second period) or the condition during which chloride transport was measured (acidosis vs. control). However, a clear effect of acidosis was to decrease $V_{\mathrm{T}}$ from $0.3 \pm 0.5 \mathrm{mV}$ at normal $\mathrm{pH}$ to $-2.1 \pm 0.2 \mathrm{mV}$ during acidosis $(P<0.05)$.

To examine the contribution of active transport to this effect of acidosis on $V_{\mathrm{T}}$, separate studies were performed in six tubules perfused in the absence and presence of luminal furosemide $\left(10^{-5} \mathrm{M}\right)$. The mean \pm SEM voltage change when solution $\mathrm{D}$ was exchanged for solution $\mathrm{A}$ in the bath (lumen always contained

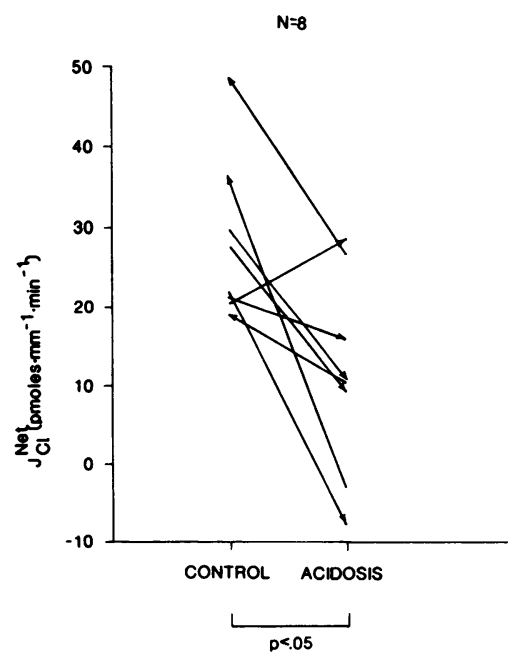

Figure 7. Effect on acidosis (decreased luminal $\mathrm{HCO}_{3}$ ) on chloride reabsorption $\left(J_{\mathrm{C}}^{\text {net }}\right)$ in cTALH. During the control and recovery periods, the luminal $\mathrm{pH}$ was $7.43 \pm 0.02$ and the $\left[\mathrm{HCO}_{3}\right]$ was $22.1 \pm 0.6$ $\mathrm{mM}$. During the experimental period the luminal $\mathrm{pH}$ was $7.12 \pm 0.005$ and the $\left[\mathrm{HCO}_{3}\right]$ was $9.83 \pm 0.35$ $\mathrm{mM}$. The arrows denote the order in which the tubule was exposed to acidosis. 
Table II. Effect of Bath Acidosis on Chloride Transport in the Absence of Luminal Potassium

\begin{tabular}{|c|c|c|c|c|c|c|c|}
\hline & \multirow[b]{2}{*}{ Length } & \multicolumn{2}{|l|}{ Flow rate } & \multicolumn{2}{|c|}{ Transepithelial voltage } & \multicolumn{2}{|l|}{ Chloride flux } \\
\hline & & Control & Experimental & Control & Experimental & Control & Experimental \\
\hline & $m m$ & $\mathrm{nl} / \mathrm{min}$ & $\mathrm{nl} / \mathrm{min}$ & $m V$ & $m V$ & $\mathrm{pmol} \cdot \mathrm{mm}^{-1} \cdot \mathrm{min}^{-1}$ & $\mathrm{pmol} \cdot \mathrm{mm}^{-1} \cdot \mathrm{min}^{-1}$ \\
\hline & 1.40 & 2.58 & 2.97 & -2.0 & -3.0 & -8.88 & 0.23 \\
\hline & 1.66 & 6.24 & 6.64 & 0.4 & -2.0 & 11.5 & -32.4 \\
\hline & 0.64 & 6.87 & 5.46 & 0.4 & -1.5 & 21.4 & -44.2 \\
\hline & 1.58 & 2.93 & 2.19 & 0.8 & -2.3 & 6.13 & 12.4 \\
\hline & 0.93 & 3.79 & 3.91 & 1.4 & -1.7 & 10.6 & -58.6 \\
\hline & 0.80 & 4.69 & 5.87 & 1.0 & -2.0 & 11.3 & 5.77 \\
\hline Mean & 1.17 & 4.52 & 4.51 & 0.3 & -2.1 & 8.68 & -19.5 \\
\hline \pm SEM & 0.18 & 0.71 & 0.72 & 0.5 & 0.2 & 4.06 & 12.0 \\
\hline
\end{tabular}

solution A) was $-2.9 \pm 0.4 \mathrm{mV}$ (from $2.4 \pm 0.2$ to $-0.5 \pm 0.2 \mathrm{mV}$ ) in the absence of furosemide. When this maneuver was repeated in the presence of luminal furosemide, the response was $-1.1 \pm 0.4 \mathrm{mV}$ (from $0.1 \pm 0.2$ to $-1.0 \pm 0.4$ ). These values are significantly different $(P<0.05)$. Thus, a component of the voltage response appears to be independent of active transport. However, the voltage response was greater in the absence of furosemide, suggesting that transcellular transport was also affected by acidosis. In five tubules perfused in the presence of luminal $\mathrm{K}$, the effect of bath isocapnic acidosis (solution $A$ to $\mathrm{D}$ exchange) on $V_{\mathrm{T}}$ was greater $(-2.8 \pm 0.7$, from $2.7 \pm 0.4$ to $-0.1 \pm 1.0)$ than the same bath exchange in the absence of luminal $\mathrm{K}(-1.0 \pm 0.2$, from $0.7 \pm 0.3$ to $-0.3 \pm 0.4)$. However, a significant $(P<0.05)$ effect of acidosis on $V_{\mathrm{T}}$ was still present in the absence of luminal $\mathrm{K}$. One tubule exhibited a transient lumen positive response before depolarizing with acidosis. Furthermore, in four tubules when the luminal fluid was exchanged (solutions $A$ and $D)$ in the presence of furosemide $\left(10^{-5} \mathrm{M}\right)$, the voltage became more lumen-positive by $1.4 \pm 0.2 \mathrm{mV}$ (from $0.1 \pm 0.1$ to $1.5 \pm 0.2$ $\mathrm{mV}$ ). Therefore, luminal acidosis would produce an even greater depolarization when corrected for this asymmetry potential.

\section{Discussion}

The present studies were designed to examine the effect of hypercapnic acidosis and isocapnic acidosis on sodium chloride transport in the cTALH in the rabbit. The main findings are: (a) in vitro hypercapnic acidosis decreases chloride reabsorption in the cTALH in the rabbit; $(b)$ this phenomenon is accompanied by a decrease in $V_{\mathrm{T}}$; and $(c)$ isocapnic acidosis due to reduced luminal or peritubular bicarbonate concentration is also associated with reduced chloride reabsorption and a concomitant decrease in $V_{\mathrm{T}}$.

It has been known for more than 30 years that acidosis results in natriuresis, kaliuresis, and chloruresis. Polak et al. (14) demonstrated that whereas the natriuresis accompanying acidosis may be variable and depend on the sodium chloride intake of the animal, chloruresis is present even with sodium chloride restriction. Recent work by Stanton and Giebisch (15) examined the effect of metabolic acidosis on potassium excretion by the whole kidney and secretion by the distal nephron. They found differences in potassium transport when in vivo microperfusion experiments were compared with free-flow micropuncture and whole kidney clearance studies. Using whole kidney clearance techniques, they observed an increased potassium excretion during metabolic acidosis. However, in their in vivo microperfusion experiments, distal nephron potassium secretion was decreased under conditions of constant luminal flow rate and peritubular acidosis. They suggested that alterations in solute delivery during metabolic acidosis might explain the differences between these outcomes, since acidosis resulted in an increase in the fractional delivery of sodium to the distal nephron. In addition, the observations of Molony et al. (5) suggest that acidosis may result in decreased sodium reabsorption in the cortical collecting tubule. Cogan (3) has shown recently that in more proximal nephron segments, hypercapnic acidosis decreases chloride reabsorption in the proximal convoluted tubule. However, the effect of acidosis on sodium chloride transport in the cTALH, a major nephron site of chloride reabsorption, has not been systematically examined by microperfusion.

In the present experiments chloride reabsorption was substantially reduced with three different maneuvers that decreased either luminal or peritubular $\mathrm{pH}$ and presumably cytosolic $\mathrm{pH}$. The work of Burg and Green (16) and Rocha and Kokko (17) first established that the nature of solute transport in the thick ascending limb is quite different from other nephron segments. Subsequently, Hebert et al. (18-20) and Greger (21) have provided evidence that chloride reabsorption in this segment is not primarily active but derives its energy from the reabsorption of sodium across the apical membrane, down its electrochemical gradient. The present studies provide clear evidence for an effect of acidosis to reduce chloride transport in the cTALH. These studies also demonstrate an effect of acidosis to depolarize $V_{\mathrm{T}}$. In view of previous evidence $(16,22)$ that isohydric luminal bicarbonate removal does not significantly alter $V_{\mathrm{T}}$, these observations are consistent with an effect of hydrogen ion concentration per se to decrease $V_{\mathrm{T}}$. At least three possible effects of acidosis could decrease transport in this segment: $(a)$ acidosis could inhibit the Na pump directly; $(b)$ acidosis could have intracellular effects such as alteration of cytosolic enzyme activity, agents that regulate transepithelial solute movement, or mitochondrial energy production; (c) acidosis could inhibit luminal $\mathrm{NaCl}$ entry. Molony et al. (5) have suggested that acidosis inhibits $\mathrm{Na}$ transport in the cortical collecting tubule by inhibiting the $\mathrm{Na}$ pump. Acidosis could directly inhibit apical $\mathrm{NaCl}$ entry also. Recent evidence suggests that $\mathrm{NaCl}$ entry is via a $\mathrm{Na}-\mathrm{K}-2 \mathrm{Cl}$ cotransport system and that $\mathrm{K}$ conductance may critically reg- 
ulate the activity of this transport system. Acidosis may inhibit sodium chloride transport by altering apical $\mathrm{K}$ conductance. Observations in the cortical collecting tubule (23) suggest that acidosis decreases potassium conductance in this structure. Similar effects of acidosis have been reported for the proximal convoluted tubule (24) and the medullary thick ascending limb of Henle (mTALH) (25). Recent work in the mTALH suggests that sodium chloride entry depends on potassium conductance and luminal potassium cotransport $(26,27)$. To examine whether potassium-coupled sodium chloride entry was critical for the inhibition of chloride transport due to acidosis, a separate set of experiments was performed in which luminal potassium was removed. In these studies chloride transport was reduced and acidosis did not significantly affect chloride transport. Although there appeared to be greater variation in the effect of acidosis on chloride transport in the cTALH in the absence of luminal $\mathrm{K}$, the simplest and most direct interpretation of these results is that chloride reabsorption depends on luminal potassium (consistent with the observations of other investigators [16, 25-27]) and that the effect of an even greater degree of peritubular acidosis cannot be demonstrated under these conditions. The degree of inhibition of chloride transport in the absence of luminal $\mathrm{K}$ is greater in the present study than in previous reports (28). The explanation for these differences is not apparent but may reflect differences in the solutions used or the method used to access chloride transport (net chloride flux in the present study vs. short circuit current estimated by cable analysis [28]). Whether luminal potassium concentration and acidosis act by the same mechanism cannot be completely answered by these studies. However, the significant effect of acidosis on $V_{\mathrm{T}}$ in this final protocol suggests that in this segment acidosis has separate or additional effects that do not depend on the presence of luminal potassium. This fact is underscored by the significant difference in the voltage response to isocapnic peritubular acidosis in the presence and the absence of active transport (luminal perfusate without or with furosemide, respectively).

The symmetrical nature of the reduction in sodium chloride reabsorption with either peritubular or luminal acidosis would also be consistent with the effect of acidosis to inhibit sodium chloride transport by an effect on cytosolic $\mathrm{pH}$. Consistent with this hypothesis is the observation that the activity of the sodium pump is highly sensitive to cytosolic pH (29). Moreover, Swenson and Maren (30) have recently demonstrated that in the shark rectal gland metabolic or respiratory acidosis of magnitude similar to that used in this study resulted in a $60 \%$ inhibition of gland flow. These authors postulated that the removal of $\mathrm{CO}_{2}$ was critical to the optimal function of the gland. Since the rectal gland is believed to transport sodium chloride in a manner similar to that of CTALH, this additional evidence is consistent with an effect of intracellular $\mathrm{pH}$ to inhibit $\mathrm{NaCl}$ transport in the cTALH.

In summary, these observations demonstrate that chloride transport in the cTALH is depressed by acidosis in vitro. In the context of whole kidney physiology, these in vitro findings may have direct clinical relevance to the effect of acidosis on solute and chloride reabsorption in CTALH in vivo.

\section{Acknowledgments}

I thank Mr. Scott Straub for his technical assistance and Mrs. Alice Cullu and Mrs. Anne Crawford for their assistance. I also thank Drs. C. Craig
Tisher, Christopher S. Wilcox, Harry R. Jacobson, and Peter A. Friedman for their criticisms and comments.

The studies were supported by funds from the Medical Research Service of the Veterans Administration and by the University of Florida Division of Sponsored Research.

\section{References}

1. Cogan, M. G., and M. R. Mueller. 1983. $\mathrm{NaHCO}_{3}$ therapy corrects the increased urinary $\mathrm{Na}, \mathrm{K}, \mathrm{Cl}$, and $\mathrm{H}_{2} \mathrm{O}$ excretion induced by $\mathrm{NH}_{4} \mathrm{Cl}$. Miner. Electrolyte Metab. 9:132-136.

2. Carter, N. W., D. W. Seldin, and H. C. Teng. 1959. Tissue and renal response to chronic respiratory acidosis. J. Clin. Invest. 38:949960.

3. Cogan, M. G. 1984. Effects of acute alterations in $\mathrm{pCO}_{2}$ on proximal $\mathrm{HCO}_{3}^{-}, \mathrm{Cl}^{-}$, and $\mathrm{H}_{2} \mathrm{O}$ reabsorption. Am. J. Physiol. 246:F21-F26.

4. Dubb, J., M. Goldberg, and Z. S. Agus. 1977. Tubular effects of acute metabolic acidosis in the rat. J. Lab. Clin. Med. 90:318-323.

5. Molony, D. A., J. P. Kokko, D. Seldin, and H. R. Jacobson. 1984. Acid peritubular pH suppresses sodium reabsorption in cortical collecting tubules. Kid. Int. 25:279. (Abstr.).

6. Burg, M., J. Grantham, M. Abramow, and J. Orloff. 1966. Preparation and study of fragments of single rabbit nephrons. Am. J. Physiol. 210:1293-1298.

7. Schafer, J. A., S. L. Troutman, and T. E. Andreoli. 1974. Volume reabsorption, transepithelial potential differences, and ionic permeability properties in mammalian superficial proximal straight tubules. J. Gen. Physiol. 64:582-607.

8. Jacobson, H. R., and J. P. Kokko. 1976. Intrinsic differences in various segments of the proximal convoluted tubule. J. Clin. Invest. 57: 818-825.

9. Ramsay, J. A., R. H. J. Brown, and P. C. Croghan. 1955. Electrometric titration of chloride in small volumes. J. Exp. Biol. 32:822-829.

10. Good, D. W., and F. S. Wright. 1980. Luminal influences on potassium secretion: transepithelial voltage. Am. J. Physiol. 239:F289F298.

11. McInnes, D. A. 1961. The Principles of Electrochemistry. Dover Publications, New York. 137-147; 231-232.

12. Kielland, J. 1937. Individual activity coefficients of ions in aqueous solutions. J. Am. Chem. Soc. 59:1675-1678.

13. Robinson, R. A., and R. H. Stokes. 1955. Electrolyte Solutions. Butterworths Scientific Publications, London. 452, 477, 479.

14. Polak, A., G. D. Haynie, R. M. Hays, and W. B. Schwartz. 1961. Effects of chronic hypercapnia on electrolyte and acid-base equilibrium. I. Adaptation. J. Clin. Invest. 40:1223-1237.

15. Stanton, B. A., and G. Giebisch. 1982. Effects of $\mathrm{pH}$ on potassium transport by renal distal tubule. Am. J. Physiol. 242:F544-F551.

16. Burg, M. B., and N. Green. 1973. Function of the thick ascending limb of Henle's loop. Am. J. Physiol. 224:659-668.

17. Rocha, A. S., and J. P. Kokko. 1973. Sodium chloride and water transport in the medullary thick ascending limb of Henle: evidence for active chloride transport. J. Clin. Invest. 52:612-623.

18. Hebert, S. C., R. M. Culpepper, and T. E. Andreoli. 1981. NaCl transport in mouse medullary thick ascending limbs. I. Functional nephron heterogeneity and $\mathrm{ADH}$-stimulated $\mathrm{NaCl}$ cotransport. Am. J. Physiol. 241:F412-F431.

19. Hebert, S. C., R. M. Culpepper, and T. E. Andreoli. 1981. NaCl transport in mouse medullary thick ascending limbs. II. ADH enhancement of transcellular $\mathrm{NaCl}$ cotransport: origin of transepithelial voltage. Am. J. Physiol. 241:F432-F442.

20. Hebert, S. C., R. M. Culpepper, and T. E. Andreoli. 1981. NaCl transport in mouse medullary thick ascending limbs. III. Modulation of the ADH effect by peritubular osmolality. Am. J. Physiol. 241:F443F451.

21. Greger, R. 1981. Chloride reabsorption in the rabbit cortical thick ascending limb of the loop of Henle. A sodium dependent process. Pfluegers Arch. Eur. J. Physiol. 390:38-43.

22. Bourdeau, J. E., and M. B. Burg. 1979. Voltage dependence of 
calcium transport in the thick ascending limb of Henle's loop. Am. J. Physiol. 236:F357-F364.

23. O'Neil, R. G., and S. C. Sansom. 1984. Characterization of apical cell membrane $\mathrm{Na}^{+}$and $\mathrm{K}^{+}$conductances of cortical collecting duct using microelectrode techniques. Am. J. Physiol. 247:F14-F24.

24. Cemerikic, D., C. S. Wilcox, and G. Giebisch. 1982. Intracellular potential and $\mathrm{K}^{+}$activity in rat kidney, proximal tubular cells in acidosis, and $\mathrm{K}^{+}$depletion. J. Membr. Biol. 69:159-165.

25. Hebert, S. C., and T. E. Andreoli. 1984. Kinetic analysis of $\mathrm{Ba}^{++}$blockade of apical membrane $\mathrm{K}^{+}$-channels in mouse medullary thick ascending limbs. Abstr. IXth Int. Congr. Nephrol. 416A.

26. Hebert, S. C., P. A. Friedman, and T. E. Andreoli. 1984. Effects of antidiuretic hormone on cellular conductive pathways in mouse medullary thick ascending limbs of Henle. I. ADH increases transcellular conductance pathways. J. Membr. Biol. 80:201-219.
27. Hebert, S. C., and T. E. Andreoli. 1984. Effects of antidiuretic hormone on cellular conductive pathways in mouse medullary thick ascending limbs of Henle. II. Determinants of the ADH-mediated increases in transepithelial voltage and in net $\mathrm{Cl}^{-}$absorption. J. Membr. Biol. 80:221-233.

28. Greger, R., and E. Schlatter. 1981: Presence of luminal $\mathrm{K}^{+}$, a prerequisite for active $\mathrm{NaCl}$ transport in the cortical thick ascending limb of Henle's loop of rabbit kidney. Pfluegers Arch. Eur. J. Physiol. 392:92-94.

29. Eaton, D. C., K. L. Hamilton, and K. E. Johnson. 1984. Intracellular acidosis blocks the basolateral Na-K pump in the rabbit urinary bladder. Am. J. Physiol. 247:F946-F954.

30. Swenson, D. R., and T. H. Maren. 1984. Effects of acidosis and carbonic anhydrase inhibition in the elasmobranch rectal gland. Am. J. Physiol. 247:F86-F92. 